\title{
Empathy, Compassion and Quality of Life in Nursing and Medical Students
}

\author{
Swati Agarwal ${ }^{1}$, Alifia Pirani ${ }^{2}$, Sadaf Mirza ${ }^{2}$ \\ ${ }^{1}$ Asst. Professor, St. Francis College for Women, Hyderabad; ${ }^{2}$ Psychologist, Hyderabad
}

\begin{abstract}
Empathy is experiencing emotions that match another person's emotions and discerning what another person is thinking or feeling. Compassion consists of three major requirements: person must feel that troubles that evoke their feelings are serious, person requires that sufferers' troubles are not self-inflicted, and the person must be able to picture themselves with the same problems. WHO defines Quality of Life as individuals' perception of their position in life in the context of the culture and value systems in which they live and in relation to their goals, expectations, standards and concerns. The present research aims to find the difference between nursing students and medical students with respect to empathy, compassion, and quality of life (viz., physical health, psychological health, social relationships and environment). Another objective of the study is to examine the relationship between empathy, compassion, and quality of life among nursing students and medical students. The study adopts a between groups design as well as a correlational design. Through purposive sampling, data was collected from 75 Nursing and 75 Medical Students, all of whom were female, by administering the tools - Measure of Emotional Empathy, Compassionate love for Humanity Scale and WHO Quality of Life Brief. Results showed that there is a difference between nursing students and medical students in empathy, compassion, quality of life and its dimensions of physical health and environment. Among nursing students, empathy was positively correlated with quality of life, whereas among medical students, empathy was negatively correlated with quality of life. These findings are relevant with respect to patients' experiences in hospitals and in the clinician - patient relationship.
\end{abstract}

Keywords: Empathy, Compassion, Quality Of Life, Nursing Students, Medical Students

\section{INTRODUCTION}

Empathy is a multidimensional construct with cognitive as well as emotive domains. Cognitive empathy is an individual's ability to understand the perspective of another individual about their circumstance and emotive empathy is an individual's concern for the feelings of others (West et al., 2006). The most common occurrences of empathy are: experiencing emotions that mimic another person's emotions, figuring out how another person is feeling and thinking, making oneself be more like the other, caring for other people and having a desire to help people in need. Most positive psychologists agree that empathetic people tend to be largely motivated by altruistic behavior (Batson et al., 1981).

Neumann, et al., (2011) reviewed the literature on empathy of medical students. It was found that eighteen studies met the inclusion criteria: eleven on medical students and seven on residents. Three longitudinal and six cross-sectional studies of medical students demonstrated a significant decrease in empathy during medical school; one cross-sectional study found a tendency toward a decrease, and another suggested stable scores. The five longitudinal and two cross-sectional studies of residents showed a decrease in empathy during residency. The studies pointed to the clinical practice phase of training and the distress produced by aspects of the "hidden," "formal," and "informal" curricula as main reasons for empathy decline.

Ward, Cody, Schaal, and Hojat, (2012) conducted a longitudinal study which was designed to examine changes in empathy. There were 214 undergraduate nursing students who completed the Jefferson Scale of Empathy. In their study they found that there was a significant decline of empathy in nursing students who were exposed more than others to patient encounters.

A commonly shared belief is that empathy is linked to one's ability to match another's emotions using sympathy; another belief is that empathy is linked to being caring and tender towards another person's emotions through the use of compassion. Empathy is like a gateway to compassion, where empathy understands how an individual feels, and trying to imagine how that might feel for you and compassion takes it one step further. It's feeling what that person is feeling, holding it, accepting it, and taking some kind of action. A typical case of an 
empathic interaction involves someone communicating an accurate response and recognition of another person's intentional actions, emotional states, and personal characteristics in a manner that is acceptable to the other person. These precise and acceptable recognitions are central features of empathy.

Suchman, Markakis, Beckman, and Frankel, (1997) did a study on 21 physicians on their Empathic Communication. In their study they found that the patients hardly verbalize their emotions directly, rather they tend to give out clues. When asked to elaborate, they tend to do so. Mostly the physicians let this pass, which is when the patients kept on focusing on the clues. This shoes that although the patients wanted to convey the message they usually didn't do so.

Compassion consists of three major requirements: People must feel that troubles that evoke their feelings are serious, people require that sufferers' troubles are not self-inflicted, and that people must be able to picture themselves with the same problems. It motivates people to provide healing for emotional, physical, or spiritual hurts. More invested than simple empathy; compassion gives rise to an active desire to alleviate another's suffering. Phillips, Davidson, Ollerton, Jackson, and Kristjanson, (2007) studied compassion in nurses and care assistants, which showed that the majority had received 'on the job training' and were committed to providing end-of-life care. Differences in the level of confidence to deal with patient/family interactions and manage complex palliative care scenarios were evident between nurses and care assistants but both groups perceived a need for further education in symptom management and communication.

Yoder (2010) studied compassion fatigue in hospital and home care nurses and found that compassion fatigue scores were significantly different between nurses who worked 8- or 12-hour shifts. Fifteen percent of the participants had scores indicating risk of the compassion fatigue. There were significant differences in compassion satisfaction, depending on the unit worked and time as a nurse with the most common category of trigger situations being caring for the patient. Markwell and Wainer, (2009) conducted a study with 914 junior doctors in which it was found that a majority of the junior doctors met low criteria for job satisfaction, burnout and compassion fatigue.

Research has suggested that the compassion is connected to the therapeutic relationship between the healthcare provider and patient (Doyle, Lennox, \& Bell, 2013). The traumatic or suffering experience of the patient sets off a response, on multiple levels, in the provider. Empathy and compassion in nurses and doctors can improve the quality of care provided to a patient (Tu, Wang, \& Yeh, 2006; Arora, 2003; Neumann et al., 2007). However, an individual's capacity for empathy and ability to engage, or enter into, a therapeutic relationship is considered to be central to compassion fatigue. Theorists have argued that individuals who display high levels of empathy and empathic response to a patient's pain, suffering, or traumatic experience are more vulnerable to experiencing compassion fatigue (Tolhurst, Adams \& Stewart, 2006; Figley, 2002, Sabo, 2011). Studies have also shown that nurses and doctors do report high stress and poor quality of life.

Thomas, et al., (2007) studied empathy, well-being, burn out, quality of life and competency in undergraduate medical students. It was found that domains of burnout inversely correlated with empathy. Symptoms of depression inversely correlated with empathy for women. In contrast, students' sense of personal accomplishment demonstrated a positive correlation with empathy independent of gender. Similarly, achieving a high quality of life in specific domains correlated with higher empathy scores. On multivariate analysis evaluating measures of distress and well-being simultaneously, both burnout (negative correlation) and wellbeing (positive correlation) independently correlated with student empathy scores.

Quality of life encompasses how an individual rates the 'good' aspects of their life. The factors affecting one's quality of life include - emotional effects of life occurrences, disposition, sense of fulfillment and satisfaction with work and personal relationships (Diener, Suh, Lucas, \& Smith, 1999). A review of medical employee stress across 17 countries found that nurses in the majority of countries experience high levels of stress and strain (Lambert \& Lambert, 2001) and nature of the work, organizational change and pressure at work contributed to high levels of ill health (Cox, Griffiths \& Cox, 1995). Poor mental health and high levels of sickness absence within the healthcare professions are likely to lead to poorer quality of patient care (Michie \& Williams 2003). Knox and Irving (1997) have also suggested that the factors involved in quality of work life can affect the work performance of healthcare workers.

This lowered quality of life among those associated with the medical profession has been observed in many studies in nursing and medical students as well, though these have not compared both in the same study. Nayak, Naidu, Krishnaveni, Sreegiri, and Srinivas (2014) studied quality of life in 250 medical students and found that 
they were weak in psychological domain of quality of life with students from an urban area having lower levels than those from students who were from a rural background. Similar results were found by Susmita, Edwin, and Braganza (2014) who studied 93 medical students and found that score decreased during the course of internship in all four domains of the instrument. A significant decline was present among women, those who reported poor sleep and individuals who had an obligation of compulsory rural service after internship.

Henning, Krägeloh, Hawken, Zhao, and Doherty (2012), assessed the quality of life of 219 individuals including Medical students, Non- Medical students and general population and found that medical students had similar quality of life perceptions to nonmedical students except in relation to the environment domain. Furthermore, the medical student group scored lower than the general population reference group on the physical health, psychological health, and environment quality of life domain.

In a study done by Suleiman, Alghabeesh, Jassem, Shahroor, and Ali, (2013) it was found that the quality of life of the nursing students was lower than that reported by the general population. The factors that significantly affected the quality of life were the employment status and demographic variables.

As already seen earlier, studies have shown that empathy and quality of life are correlated (Thomas, et al., 2007) for medical students and compassion and quality of life were correlated too (Yoder, 2010). Although these variables have been studied before, there is dearth of studies showing the relationship between the three variables in the specific sample of medical and nursing students. The objectives of the present study were to see the relationship between empathy, compassion and quality of life among nursing students and medical students.

\section{Research Design}

\section{METHOD}

A between groups design has been used in the present study to examine the differences in the levels of empathy, compassion and quality of life between female medical students and female nursing students. The study also adopts a Correlational Design where the relationship between the Empathy, Compassion and Quality of Life was analyzed among the nursing and the medical students.

\section{Sample}

For the present study, a sample of 150 female students was chosen by purposive sampling out of which 75 were medical students and 75 were nursing students. The inclusion criteria for medical students was - a) they must be pursuing their medical degree (MBBS), b) they must be in the $2^{\text {nd }}$ or $3^{\text {rd }}$ year of the medical degree, $c$ ) the students must be between the age of 20 to 25 years. Students pursuing dentistry were excluded from the sample. For the sample of nursing students the inclusion criteria is as follows - a) they must be pursuing nursing degree, b) they must be in their $2^{\text {nd }}$ or $3^{\text {rd }}$ year the nursing degree, c) the students must be between the age of 20 to 25 years. Male students were not included in the study as in India nursing courses is dominated by females with male nurses being rare exceptions in the profession.

\section{Instruments}

A personal information schedule was administered for collecting basic demographic details such as age, residence, religion, relationship status, educational status, living arrangements, physical and mental health status of the participants.

The first tool used in the study was the Measure of Emotional Empathy scale developed by Caruso and Mayer (1998) to measure the individual's empathy. It is a 30 item on a five point likert scale which has a high reliability of 0.70. Compassion was measured using the Compassionate love for Humanity Scale developed by Sprecher and Fehr (2005). It is a 21 item unidimensional scale with responses on a 7 point likert scale. It has a high reliability of 0.86. To measure the Quality of Life, the WHO - Quality of Life BREF (WHOQOL - BREF) was chosen and this was developed in 1996. This scale has 26 items and 4 dimensions namely physical health, psychological health, social relationships and environment. The responses for each item are on a five point Likert Scale. This scale's internal consistency reliability is between 0.66 and 0.80 .

\section{Procedure}

The chosen sample groups were recruited by approaching medical and nursing colleges and obtaining their permission for data collection. Students meeting the inclusion criteria were approached and those willing to participate were briefed about the study and their informed consent was taken. None of the participants were compensated and their participation was voluntary. The obtained quantitative data of this study were analyzed 
using Independent t-test and Pearson's product moment correlation using the Statistical Package for Social Sciences (SPSS) version 20.0.

\section{RESULTS}

Results of the independent t-test to analyze the differences between the nursing students and medical students on their levels of empathy, compassion and quality of life are presented in Table 1. It can be seen that nursing students had higher levels of empathy and compassion in comparison to the students who were pursuing their medicine. Medical students reported better social relationships in the dimension of quality of life, barring which no differences were found in the quality of life of nursing and medical students with respect to the dimensions of physical health, psychological health and environment.

Table 1 -Mean, Standard Deviation and $t$ value for the sample of Nursing Students and Medical Students

\begin{tabular}{|c|c|c|c|c|c|}
\hline \multirow[t]{2}{*}{ Variable } & \multicolumn{2}{|c|}{ Nursing Students } & \multicolumn{2}{|c|}{ Medical Students } & \multirow[t]{2}{*}{$\mathrm{t}$} \\
\hline & Mean & SD & Mean & SD & \\
\hline Empathy & 105.24 & 8.86 & 96.95 & 12.86 & $4.599 * *$ \\
\hline Compassion & 114.87 & 12.38 & 107.47 & 16.31 & $3.130 * *$ \\
\hline Quality of Life & 79.96 & 6.56 & 81.08 & 8.02 & -.936 \\
\hline Physical Health & 20.33 & 1.91 & 20.36 & 2.79 & -.068 \\
\hline Psychological Health & 21.51 & 2.33 & 21.43 & 2.94 & .185 \\
\hline Social Relationships & 11.16 & 1.35 & 12.01 & 1.89 & $-3.182 * *$ \\
\hline Environment & 26.96 & 2.73 & 27.28 & 3.12 & -.668 \\
\hline
\end{tabular}

Table 2 and Table 3 show the correlation matrices of empathy, compassion and quality of life and its dimensions in nursing students and medical students. Among the nursing students, empathy was found to positively related with compassion, physical health and negatively related to environment dimension of quality of life. In the same group, compassion had a positive relationship with physical health only and did not have any significant relationships with the other dimensions of quality of life.

Table 2 - Correlation between Empathy, Compassion, Quality of Life and its dimensions of Physical Health, Psychological Health, Social Relationships and Environment among Nursing Students (N=75).

\begin{tabular}{|c|c|c|c|c|c|c|}
\hline Variable & 2 & 3 & 4 & 5 & 6 & 7 \\
\hline 1. Empathy & $.851^{* *}$ & $.264^{*}$ & -.173 & .109 & $-.396^{* * *}$ & -.127 \\
\hline 2. Compassion & 1 & $.474^{* * *}$ & .175 & .118 & -.013 & .219 \\
\hline 3. Physical Health & & 1 & $.620^{* *}$ & $.651^{* *}$ & $.375^{* *}$ & $.802^{* *}$ \\
\hline $\begin{array}{l}\text { 4. Psychological } \\
\text { Health }\end{array}$ & & & 1 & $.509^{* * *}$ & $.523^{* *}$ & $.858^{* * *}$ \\
\hline $\begin{array}{ll}\text { 5. } & \text { Social } \\
& \text { Relationships }\end{array}$ & & & & 1 & $.271^{*}$ & $.689^{* *}$ \\
\hline 6. Environment & & & & & 1 & $.768^{* * *}$ \\
\hline 7. Quality of Life & & & & & & 1 \\
\hline
\end{tabular}

Note $-* \mathrm{p}<0.05, * * \mathrm{p}<0.01$

Among the medical students, results for the correlation analyses show that though empathy had a positive relationship with compassion, it had significant negative relationships with quality of life and all its dimensions, that is, physical health, psychological health, social relationships and environment. Compassion was also negatively related to physical health, social relationships and overall quality of life but was not related to psychological health and environment.

Table 3 - Correlation between Empathy, Compassion, Quality of Life and its dimensions of Physical Health, Psychological Health, Social Relationships and Environment among Medical Students $(N=75)$.

\begin{tabular}{|c|c|c|c|c|c|c|}
\hline Variable & 2 & 3 & 4 & 5 & 6 & 7 \\
\hline 1. Empathy & $.589^{* *}$ & $-.279^{*}$ & $-.414^{* *}$ & $-.592^{* * *}$ & $-.399^{* *}$ & $-.544^{* *}$ \\
\hline 2. Compassion & 1 & $-.412^{* * *}$ & -.085 & $-.531^{* * *}$ & -.211 & $-.382^{* * *}$ \\
\hline 3. Physical Health & & 1 & $.325^{* * *}$ & $.283^{*}$ & .029 & $.545^{* *}$ \\
\hline $\begin{array}{l}\text { 4. Psychological } \\
\text { Health }\end{array}$ & & & 1 & $.667^{* * *}$ & $.640^{* *}$ & $.887^{* *}$ \\
\hline $\begin{array}{ll}\text { 5. } & \text { Social } \\
& \text { Relationships }\end{array}$ & & & & 1 & $.551^{* *}$ & $.794^{* * *}$ \\
\hline
\end{tabular}




\begin{tabular}{|l|l|l|l|l|l|c|}
\hline 6. & Environment & & & & 1 & $\mathbf{. 7 6 4}$ \\
\hline 7. Quality of Life & & & & & & 1 \\
\hline
\end{tabular}

\section{DISCUSSION}

The objectives of the present study were to see if female nursing and medical students differed on empathy, compassion and quality of life. Results show that nursing students were higher on empathy and compassion than medical students. Fields et al. (2004) have found that nurses and physicians do not differ on empathy levels. However, other studies report that health care providers differ in the empathy they display in their interactions in the hospital (Reynolds \& Scott, 2000; Wilkes, Milgrom, \& Hoffman, 2002). Further studies show that empathy levels decline in medical students as they move ahead in their learning and training period (Diseker \& Michielutte, 1981; Neumann et al., 2011). Haslam (2007) reports a number of factors both individual and environmental that precipitate this decline. Individual factors include - increasing cynicism, loss of hope when experiencing therapeutic failure and a self protective measure of becoming disengaged from the patients, displaying impartiality and improving concentration. Environmental factors consist of reliance on technology to aid diagnosis, treatment and care; economic and time constraints, etc. that force care providers to compromise on their interactions with the patients.

In the present study nursing and medical students did not differ in their overall quality of life and its dimensions of physical health, psychological health and environment (Henning, Krageloh, Hawken, Zhao, \& Doherty, 2012). However, medical students reported better social relationships than nursing students. Research indicates that the rigors of medical school and experiencing medical burden (Angkurawaranon, et al., 2016) adversely affect the quality of life of medical students (Tempski, et al. 2012). Nursing students also undergo similar academic rigor and medical burden leading to poor quality of life in them, which has been seen in numerous studies across countries (Eurich \& Kluthcovsky, 2008; Suleiman, Alghabeesh, Jassem, Abu-Shahroor, \& Ali, 2013; de Araujo, et al., 2015).

Examining the relationship between empathy, compassion and quality of life in nursing students shows that empathy and compassion are positively associated with physical health. Empathy has a negative relationship with environment dimension of quality of life. Duarte, Pinto-Gouveia and Cruz (2016) have found that empathy predicted professional quality of life in nurses. Empathy is associated with altruistic behaviour which is linked to positive emotions. The beneficial effects of positive emotions on physical health have been noted in many studies. Williams (1989) had found that empathy in nurses may lead to emotional exhaustion, which in turn can lead to depersonalization, if it is not ameliorated by personal accomplishment.

Among the medical students, empathy was negatively related to quality of life and its dimensions, that is, physical health, psychological health, social relationships and environment. Compassion was also negatively related to physical health, social relationships, environment and overall quality of life. Increase in empathy leads to poor quality of life and decrease in empathy improves the quality of life of medical students. Research shows that there is a decline in the levels of empathy in medical students and one of the factors is self protective measure against the increasing therapeutic burden. As medical students are initiated into the medical field and exposed to clinical experience, where they have to interact with patients and work towards their care, they may not be adept at dealing with the emotional demands of the training, especially when they are more empathetic towards their patients. The demand to be extremely resilient and not display emotional weakness, such as by crying, may further add to the emotional burden of the students. This may have an adverse impact on their well being and quality of life. Thus, they may slowly start to withdraw and use detachment as a coping measure when they start experiencing poor well being and quality of life (Haslam, 2007).

The present study is limited by the sample which includes only female medical students, and it's cross sectional nature which precludes causation. However, very few studies have looked into comparing nursing and medical students with respect to their empathy, compassion and quality of life, particularly in India and hence this study furthers knowledge about the healthcare professionals. Medical students experience poor quality of life with increasing empathy and compassion and this could be a possible reason why they display lower empathy and compassion than the nursing students. However, studies have established that empathy and compassion improve the quality of doctor patient interaction, patient compliance and adherence. Medical students have to be trained to increase their empathy and compassion. At the same time, they have to be taught techniques to cope with the emotional demands of their profession so that they do not succumb to stress and burnout and also prevent compassion fatigue in them. 
The Indian health care system already faces a shortage of trained medical professionals and the existing care providers cannot be lost to stress and burnout. Intervention modules have to be incorporated in the curricula of healthcare programs that teach students how to experience and display empathy and compassion in their interactions with the patients. Further, resilience training has to be provided to the students from the first year of medical and nursing school so that they are able to cope with the academic rigors as well as the medical and therapeutic burden of their profession.

\section{REFERENCES}

[1] Angkurawaranon, C., Jiraporncharoen, W., Sachdev, A., Wisetborisut, A., Jangiam, W., \& Uaphanthasath, R. (2016). Predictors of quality of life of medical students and a comparison with quality of life of adult health care workers in Thailand. SpringerPlus, 5(1), 584.

[2] Arora, N. K. (2003). Interacting with cancer patients: the significance of physicians' communication behavior. Social science \& medicine, 57(5), 791-806.

[3] Batson, C. D., Duncan, B. D., Ackerman, P., Buckley, T., \& Birch, K. (1981). Is empathic emotion a source of altruistic motivation?. Journal of personality and Social Psychology, 40(2), 290.

[4] Caruso, D. R., \& Mayer, J. D. (1998). A measure of emotional empathy for adolescents and adults. Unpublished manuscript, 713-726.

[5] Cox, T., Griffiths, A., \& Cox, S. (1995). Work-Related Stress in Nursing: Managing the Risk. Geneva: International Labour Organization.

[6] de Araujo, M. A. N., Lunardi Filho, W. D., Leite, L. R. C., Ma, R. T. K., da Silva, A. A., \& Souza, J. C. (2015). Qualidade de vida de estudantes de enfermagem. Northeast Network Nursing Journal, 15(6).

[7] Diseker, R. A., \& Michielutte, R. (1981). An analysis of empathy in medical students before and following clinical experience. Academic Medicine, 56(12), 1004-10.

[8] Doyle, C., Lennox, L., \& Bell, D. (2013). A systematic review of evidence on the links between patient experience and clinical safety and effectiveness. BMJ open, 3(1), e001570.

[9] Duarte, J., Pinto-Gouveia, J., \& Cruz, B. (2016). Relationships between nurses' empathy, selfcompassion and dimensions of professional quality of life: A cross-sectional study. International Journal of Nursing Studies, 60, 1-11.

[10] Diener, E., Suh, E. M., Lucas, R. E., \& Smith, H. L. (1999). Subjective well-being: Three decades of progress. Psychological Bulletin, 125(2), 276-302.

[11] Eurich, R. B., \& Kluthcovsky, A. C. G. (2008). Evaluation of quality of life of undergraduate nursing students from first and fourth years: the influence of sociodemographic variables. Revista de Psiquiatria do Rio Grande do Sul, 30(3), 211-220.

[12] Fields, S. K., Hojat, M., Gonnella, J. S., Mangione, S., Kane, G., \& Magee, M. (2004). Comparisons of nurses and physicians on an operational measure of empathy. Evaluation \& the health professions, 27(1), 80-94.

[13] Figley, C. R. (2002). Compassion fatigue: Psychotherapists' chronic lack of self care. Journal of clinical psychology, 58(11), 1433-1441.

[14] Haslam, N. (2007). Humanising medical practice: the role of empathy. Medical journal of Australia, 187(7), 381.

[15] Henning, M. A., Krägeloh, C. U., Hawken, S. J., Zhao, Y., \& Doherty, I. (2012). The quality of life of medical students studying in New Zealand: a comparison with nonmedical students and a general population reference group. Teaching and learning in medicine, 24(4), 334-340.

[16] Knox, S., \& Irving, J. A. (1997). An interactive quality of work life model applied to organizational transition. Journal of Nursing Administration, 27(1), 39-47.

[17] Lambert, V. A., \& Lambert, C. E. (2001). Literature review of role stress/strain on nurses: an international perspective. Nursing \& health sciences, 3(3), 161-172.

[18] Markwell, A. L., \& Wainer, Z. (2009). The health and wellbeing of junior doctors: insights from a national survey. Medical Journal of Australia, 191(8), 441.

[19] Michie, S., \& Williams, S. (2003). Reducing work related psychological ill health and sickness absence: a systematic literature review. Occupational and environmental medicine, 60(1), 3-9.

[20] Nayak, M. S. D. P., Naidu, S. A., Krishnaveni, A., Sreegiri, S., \& Srinivas, P. J. (2014). Quality Of Life in Medical Students of Andhra Medical College, Visakhapatnam. International Journal of Health Sciences and Research (IJHSR), 4(12), 39-43.

[21] Neumann, M., Edelhäuser, F., Tauschel, D., Fischer, M. R., Wirtz, M., Woopen, C.,...\& Scheffer, C. (2011). Empathy decline and its reasons: a systematic review of studies with medical students and residents.Academic medicine, 86(8), 996-1009. 
[22] Neumann, M., Wirtz, M., Bollschweiler, E., Mercer, S. W., Warm, M., Wolf, J., \& Pfaff, H. (2007). Determinants and patient-reported long-term outcomes of physician empathy in oncology: a structural equation modelling approach. Patient education and counseling, 69(1), 63-75.

[23] Phillips, J. L., Davidson, P. M., Ollerton, R., Jackson, D., \&Kristjanson, L. (2007). A survery of commitment and compassion among nurses in residential aged care. International journal of palliative nursing, 13(6), 282-290.

[24] Reynolds, W. J., \& Scott, B. (2000). Do nurses and other professional helpers normally display much empathy?. Journal of advanced nursing, 31(1), 226-234.

[25] Sabo, B. (2011). Reflecting on the concept of compassion fatigue. Online journal of issues in nursing, 16(1).

[26] Saxena, S., Orley, J., \& WHOQOL Group. (1997). Quality of life assessment: the World Health Organization perspective. European psychiatry, 12, 263s-266s.

[27] Sprecher, S., \& Fehr, B. (2005).Compassionate love for close others and humanity. Journal of Social and Personal Relationships, 22(5), 629-651.

[28] Suchman, A. L., Markakis, K., Beckman, H. B., \& Frankel, R. (1997). A model of empathic communication in the medical interview. Jama, 277(8), 678-682.

[29] Suleiman, K., Alghabeesh, S., Jassem, H., Shahroor, L., \& Ali, R. (2013). Quality of life (QOL) among university students in Jordan: A Descriptive study. Journal of Education and Practice, 4 (11), 161, 167.

[30] Susmita, C., Edwin, N., \& Braganza, D. (2014). Quality of life among interns at a southern Indian tertiary care hospital: a cohort study.

[31] Tempski, P., Bellodi, P. L., Paro, H. B., Enns, S. C., Martins, M. A., \& Schraiber, L. B. (2012). What do medical students think about their quality of life? A qualitative study. BMC medical education, $12(1), 1$.

[32] Thomas, M. R., Dyrbye, L. N., Huntington, J. L., Lawson, K. L., Novotny, P. J., Sloan, J. A., \& Shanafelt, T. D. (2007). How do distress and well-being relate to medical student empathy? A multicenter study. Journal of General Internal Medicine, 22(2), 177-183

[33] Tolhurst, H., Adams, J., \& Stewart, S. (2006). An exploration of when urban background medical students become interested in rural practice. Rural and Remote Health Journal, 6(1, Article No 452), 111.

[34] Tu, Y. C., Wang, R. H., \& Yeh, S. H. (2006). Relationship between perceived empowerment care and quality of life among elderly residents within nursing homes in Taiwan: A questionnaire survey. International Journal of Nursing Studies, 43(6), 673-680.

[35] Ward, J., Cody, J., Schaal, M., \& Hojat, M. (2012). The empathy enigma: an empirical study of decline in empathy among undergraduate nursing students. Journal of Professional Nursing, 28(1), 34-40.

[36] West, C. P., Huschka, M. M., Novotny, P. J., Sloan, J. A., Kolars, J. C., Habermann, T. M., \& Shanafelt, T. D. (2006). Association of perceived medical errors with resident distress and empathy: a prospective longitudinal study. Jama, 296(9), 1071-1078.

[37] Wilkes, M., Milgrom, E., \& Hoffman, J. R. (2002). Towards more empathic medical students: a medical student hospitalization experience. Medical education, 36(6), 528-533.

[38] Williams, C. A. (1989). Empathy and burnout in male and female helping professionals. Research in Nursing \& Health, 12(3), 169-178.

[39] Yoder, E. A. (2010). Compassion fatigue in nurses. Applied Nursing Research, 23(4), 191-197. 